\title{
Dissemination of Class 1, 2 and 3 Integrons among Different Multidrug Resistant Isolates of Acinetobacter baumannii in Tehran Hospitals, Iran
}

\author{
MOROVAT TAHERIKALANI ${ }^{1,2^{*}}$, ABBAS MALEKI $^{2}$, NOURKHODA SADEGHIFARD ${ }^{1,2}$, \\ DELBAR MOHAMMADZADEH ${ }^{3}$, SETAREH SOROUSH ${ }^{2}$, PARISA ASADOLLAHI ${ }^{2}$, \\ KHAIROLLAH ASADOLLAHI ${ }^{4}$ and MOHAMMAD EMANEINI ${ }^{5}$
}

\author{
${ }^{1}$ Department of Medical Microbiology, School of Medicine, Ilam University of Medical Sciences, Ilam, Iran \\ ${ }^{2}$ Clinical Biology Research Center, Ilam University of Medical Sciences, Ilam, Iran \\ ${ }^{3}$ Department of Microbiology, Science and Research Branch, Islamic Azad University of Tehran, Iran \\ ${ }^{4}$ Department of Epidemiology, School of Medicine, Ilam University of Medical Sciences, Ilam, Iran \\ ${ }^{5}$ Department of Microbiology, School of Medicine, Tehran University of Medical Sciences, Tehran, Iran
}

Received 3 January 2011, revised 10 April 2011, accepted 12 April 2011

\section{Abstract}

A total of 100 non-duplicate Acinetobacter baumannii isolates were collected from different hospitals in Tehran and were confirmed as A. baumannii by conventional biochemical and API testing. Antimicrobial susceptibility of these isolates was checked by a disk diffusion method in accordance with CLSI guidelines. The isolates were then detected as carrying class 1 and 2 integron gene cassettes by PCR evaluation and then genotyped by REP-PCR. More than $50 \%(n=50)$ of the isolates were multidrug resistant. The results showed that more than $80 \%$ of all multidrug resistant A. baumannii strains carry a class 1 integron. Distribution of IntI 1 and IntI2 among A. baumannii isolates was $58 \%$ and $14 \%$, respectively. Analysis of a conserved segment of class 1 integron showed a range from $100 \mathrm{bp}$ to $2.5 \mathrm{~kb}$. REP-PCR fingerprinting showed more than 20 genotypes among A. baumannii strains. There was no relationship between REP genotypes and the distribution of different classes of integrons. This is a comprehensive study on the distribution of different classes of integrons among A. baumannii in Iran. Considering the exact role of integrons in coding drug resistance in bacteria, the findings of this study could help us find antimicrobial resistant mechanisms among A. baumannii isolates in Iran.

Ke y word s: A. baumannii, hospital isolates in Iran, integron classes

\section{Introduction}

Acinetobacter baumannii is an important opportunistic pathogen responsible for a variety of nosocomial infections, including ventilator-associated pneumonia, bacteremia, surgical-site infections, secondary meningitis, and urinary tract infections (von Dolinger et al., 2005; Fontana et al., 2008; Peleg et al., 2008).

Most A.baumannii infections are caused by the outbreak strains, which can spread widely and rapidly between patients. Since these strains also exhibit multiple-antibiotic resistance, it has been suggested that epidemic potential among isolates of $A$. baumannii may be linked to the presence of integrons.

Integrons are DNA elements capable of capturing genes by a site-specific recombination mechanism that often carry gene cassettes, containing antibiotic resistance genes (Turton, et al., 2005). Various studies have reported the existence of antibiotic resistance genes located on integrons among Acinetobacter spp. (Gallego and Towner 2001; Navia et al., 2002; Nemec et al., 2004; Zarrilli et al., 2004).

Several classes of integrons have been described, with class I integrons being the most common and widely distributed among Gram-negative bacteria. Integrons have been found in isolates of Acinetobacter spp. from different locations of the world and it has been suggested that multi-resistant isolates of Acinetobacter spp. may act as a reservoir of integron-associated antibiotic resistance gene, which could then spread to other pathogens in the hospital environment (Gallego and Towner 2001).

Few studies have hitherto focused on the distribution of antibiotic resistance genes among Acinetobacter spp. in Iran (Feizabadi et al., 2008; Taherikalani et al., 2008; Taherikalani et al., 2009; Akbari et al., 2010); however, there is limited information on the detection of different classes of integrons in Iran.

This study aimed to determine the distribution of class 1, 2 and 3 integrons among A. baumannii isolates, collected from different clinical specimens in selected

* Corresponding author: M. Taherikalani, Department of Microbiology, School of Medicine, and Clinical Microbiology Research Center, Ilam University of Medical Sciences, Banganjab, Ilam, IR of Iran, Postal Zip: 69391-77143; phone: +98-841-223-5747; fax. +98-841-2227136; e-mail: taherikalani@gmail.com 
hospitals, in Tehran and to evaluate any correlations between antibiotic resistance and the carriage of different classes of integrons among $A$. baumannii isolates.

\section{Experimental}

\section{Materials and Methods}

Bacterial isolates. A total of 100 non-duplicate isolates of Acinetobacter spp. were collected from different clinical specimens during 2007-2009. These isolates were confirmed as A. baumannii by conventional biochemical testing and 20NE API galleries (BioMerieux, Inc) used in the previous studies (Feizabadi et al., 2008; Taherikalani et al., 2009; Akbari et al., 2010). These studies were carried out in the laboratory of microbiology in Ilam University, Iran. Fifty six percent $(n=56)$ of the isolates were recovered from wound and trachea. The strains isolated were then stored at $-80^{\circ} \mathrm{C}$ in nutrient broth containing $50 \%$ glycerol $\mathrm{v} / \mathrm{v}$ for further investigation.

Antimicrobial susceptibility testing. Antimicrobial susceptibility testing was performed by disk agar diffusion, according to CLSI guidelines. The applied antimicrobials were as follows: ampicillin-sulbactam $(10 / 10 \mu \mathrm{g})$, piperacillin $(100 \mu \mathrm{g})$, cefotaxime $(30 \mu \mathrm{g})$, ceftazidime $(30 \mu \mathrm{g})$, cefteriaxone $(30 \mu \mathrm{g})$, cefepime $(30 \mu \mathrm{g})$, imipenem $(10 \mu \mathrm{g})$, ciprofloxacin $(5 \mu \mathrm{g})$, amikacin $(30 \mu \mathrm{g})$, gentamicin $(10 \mu \mathrm{g})$ and tetracycline $(10 \mu \mathrm{g})$. Inoculums of the A. baumannii isolates $\left(10^{6} \mathrm{CFU}\right)$ were swabbed on several Muller-Hinton agar plates, and different disks, impregnated each with different antibiotics, were then placed on these plates. Incubation at $37^{\circ} \mathrm{C}$ for $24 \mathrm{~h}$ was then carried out after which the inhibition zones were read. Escherichia coli ATCC 25922, Staphylococcus aureus ATCC 29213 and Pseudomonas aeruginosa ATCC 27853 were used as control strains.

PCR amplification of integron-associated genes for different integron classes. DNA extraction was carried out using commercial standard kit (Bioner, Republic of Korea) and $4 \mu$ of the suspension were used as the template DNA for PCR.
PCR annealing temperature, primer sequences and the amplicon sizes are listed in Table I (Srinivasan, Rajamohan et al., 2009).

The PCR conditions were as follows: initial denaturation at $95^{\circ} \mathrm{C}$ for $5 \mathrm{~min} ; 30$ cycles with denaturation at $95^{\circ} \mathrm{C}$ for $30 \mathrm{~s}$, annealing at $50^{\circ} \mathrm{C}, 51^{\circ} \mathrm{C}, 52^{\circ} \mathrm{C}$ and $53^{\circ} \mathrm{C}$ for 30 s for integrons class 1,2 and 3 and conserved sequence of integron class 1 respectively, and extension at $72^{\circ} \mathrm{C}$ for $45 \mathrm{~s}$ followed by final extension at $72^{\circ} \mathrm{C}$ for $7 \mathrm{~min}$. PCR products were separated by electrophoresis on a $1 \%$ agarose gel and were detected by comparison against a 100 bp DNA ladder as a size marker under the visualization of UV light on Geldoc apparatus.

REP-PCR Finger-printing. DNA extraction was carried out by DNA extraction kit (Bioner, Republic of Korea) and $4 \mu \mathrm{l}$ of the extract was used as the template DNA. The primer pair REP1, 5'-IIIGCGCCGICATCAGGC-3' and REP2, 5'-ACGTCTTATCAGGCCTAC-3' were used to amplify putative REP-like elements in the genomic bacterial chromosomes (Bou et al., 2000). Amplification reaction was performed in a final volume of $25 \mu$ l. Each reaction mixture contained $2.5 \mu$ l of 10X PCR buffer, 1.25 U Taq DNA polymerase (Fermentas, UK), and $0.8 \mu \mathrm{l}$ of mixed dNTPs (Fermentas, UK), $1.5 \mu \mathrm{l}$ of $25 \mathrm{Mm} \mathrm{MgCl}_{2}, 1 \mu \mathrm{l}$ of $10 \mathrm{pmol}$ primers and $50 \mathrm{ng}$ of bacterial DNA. Amplification reaction was carried out by thermal cycler (Ependorff, Germany) with an initial denaturation at $94^{\circ} \mathrm{C}$ for $10 \mathrm{~min}$, followed by 30 cycle of denaturation at $94^{\circ} \mathrm{C}$ for $1 \mathrm{~min}$, annealing at $45^{\circ} \mathrm{C}$ for $1 \mathrm{~min}$, and extension at $72^{\circ} \mathrm{C}$ for $1 \mathrm{~min}$, followed by final extension at $72^{\circ} \mathrm{C}$ for $16 \mathrm{~min}$. Aliquots of each sample were subjected to electrophoresis in $1.2 \%$ agarose gels. Amplified products were detected by Geldoc apparatus after staining with ethidium bromide $(50 \mathrm{mg} / \mathrm{L})$ and the created photographs were then analysed visually and with the TotalLab TL120 software.

\section{Results}

The most effective antimicrobial agents against $A$. baumannii isolates were as follows: gentamicin $55 \%(n=55)$, imipenem 47\% ( $n=47)$, ampicillin-sulbactam, ami-

Table I

Primers used in PCR amplification of integron classes 1 to 3

\begin{tabular}{|l|l|l|c|c|}
\hline \multicolumn{1}{|c|}{ Target gene } & \multicolumn{1}{|c|}{ Forward } & Reverse & $\begin{array}{c}\text { Annealing } \\
\text { Temperature } \\
\left({ }^{\circ} \mathrm{C}\right)\end{array}$ & $\begin{array}{c}\text { Size of } \\
\text { amplicon } \\
(\mathrm{bp})\end{array}$ \\
\hline intI 1 & 5'-ACATGTGATGGCGACGCACGA-3' & $5^{\prime}$-ATTTCTGTCCTGGCTGGCGA-3' & 50 & 300 \\
\hline intI 2 & 5'-CACGGATATGCGACAAAAAGGT-3' & 5'-GTAGCAAACGAGTGACGAAATG-3' & 51 & 962 \\
\hline intI 3 & 5'-GCCTCCGGCAGCGACTTTCAG-3' & 5'-ACGGATCTGCCAAACCTGACT-3' & 52 & 1041 \\
\hline $\begin{array}{l}\text { Conserved } \\
\text { Segment of IntI 1 }\end{array}$ & (5'-CS) 5'-GGCATCCAAGCAGCAAG-3' & (3'-CS) 5'-AAAGCAGACTTGACCTGA-3' & 53 & Variable \\
\hline
\end{tabular}




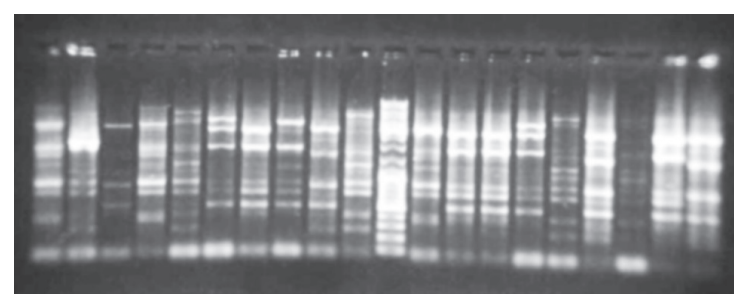

Fig. 1. Variable amplicon size of conserved segments of integron class 1.

Lane 1 (negative control: DDW); Lanes 3 and 8 (clinical positive sample); Lanes 2 and 4-7 and 9-11 and 13-21 (clinical negative samples).

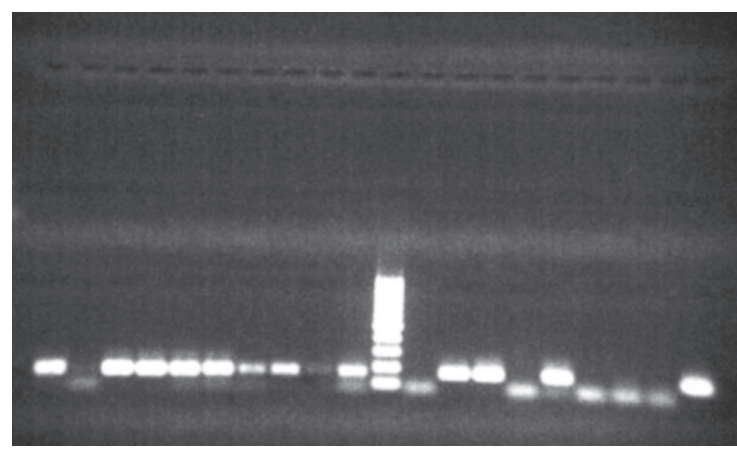

Fig. 2. PCR of class 1 integron among clinical A. baumannii isolates. Lanes 1-2, 4-5, 7-8, 10 (clinical positive isolates), Lane 11 (100 bp DNA size marker), Lanes 12-20 (clinical positive isolates).

kacin 38\% ( $\mathrm{n}=38)$ and tetracycline $31 \%(\mathrm{n}=31)$. Most isolates showed high resistance to piperacillin (100\%) and_cephalosporin drugs (more than 95\%).

The REP- fingerprinting of some A. baumannii isolates are shown in Fig. 1. All the isolates not previously compared with REP or other typing methods were revealed to have 20 REP patterns. No reliable REP pattern was observed among 15 isolates.

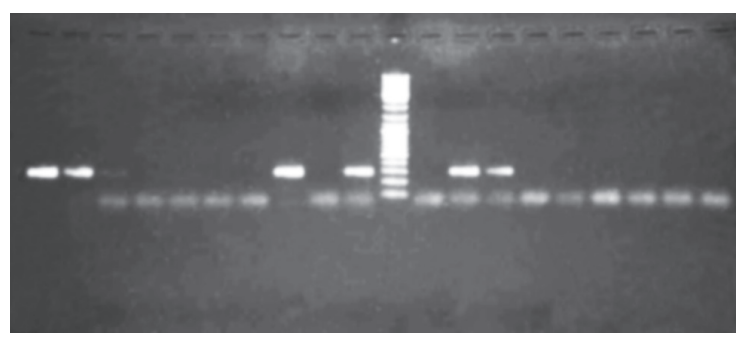

Fig. 3. PCR of class 2 integron among clinical A. baumannii isolates. Lanes 1-2, 8, $913-14$ (clinical positive isolates), Lane 11 (100 bp DNA size marker); Lanes 3-7, 9, 12, 15-20 (clinical negative isolates).

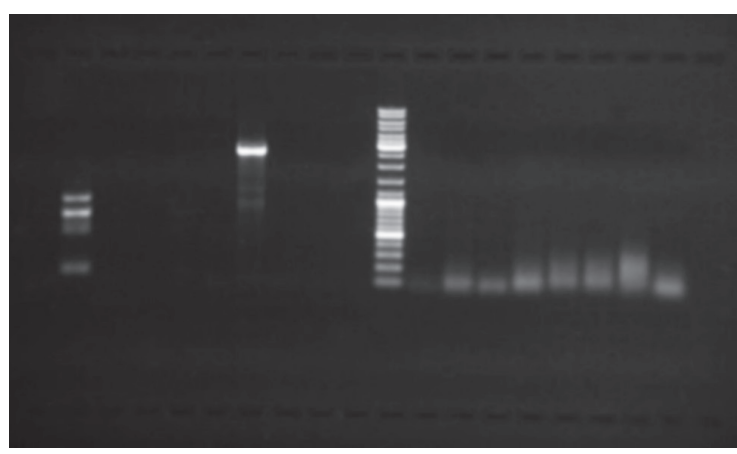

Fig. 4. REP PCR. Pattern of genomic DNA from 19 clinical A. baumannii isolates.

Lanes 1-10, 12-20 (clinical isolates of A. baumannii), Lane 11 (DNA Ladder $100 \mathrm{bp}$ to $3000 \mathrm{bp}$ ).

PCR detecting integrase gene showed that $58 \%(n=58)$ of all the isolates had intI 1; however, intI 2 was only identified in $14 \%(\mathrm{n}=14)$ of the isolates and intI 3 was not revealed in any of the clinical isolates. The coexistence rate of intI 1/intI 2 was $9 \%(\mathrm{n}=9)$. The relationship between antibiotic resistance and the existence of different integrons is shown in Table II. More than 50\% of penicillin and cephalosporin resistant isolates har-

Table II

Distribution of intI 1 and intI 2 among A. baumannii isolates resistant to different antibiotic agents

\begin{tabular}{|l|c|c|c|c|}
\hline \multicolumn{1}{|c|}{ Antibiotic agent } & $\begin{array}{c}\text { Number of resistant } \\
\text { isolates t }\end{array}$ & $\begin{array}{c}\text { Class 1 integron } \\
\mathrm{n}(\%)\end{array}$ & $\begin{array}{c}\text { Class 1\&2 } \\
\text { integrons n (\%) }\end{array}$ & $\begin{array}{c}\text { Class 2 integron } \\
\mathrm{n}(\%) \mathrm{t}\end{array}$ \\
\hline Piperacillin & 100 & $58(58)$ & $14(14)$ & $9(9)$ \\
\hline Ampicillin- sulbactam & 62 & $24(37.5)$ & $3(4.83)$ & $1(1.61)$ \\
\hline Ciprofloxacin & 85 & $51(60)$ & $14(16.4)$ & $9(10.58)$ \\
\hline Amikacin & 62 & $27(43.54)$ & $10(16.12)$ & $7(11.29)$ \\
\hline Imipenem & 53 & $24(45.28)$ & $7(13.20)$ & $4(7.54)$ \\
\hline Cefotaxime & 97 & $57(58.76)$ & $13(13.4)$ & $9(9.27)$ \\
\hline Cefepime & 99 & $58(58.58)$ & $14(14.14)$ & $9(9.09)$ \\
\hline Ceftazidime & 97 & $57(58.76)$ & $13(13.4)$ & $9(9.27)$ \\
\hline Ceftriaxone & 97 & $56(57.73)$ & $14(14.43)$ & $9(9.27)$ \\
\hline Tetracycline & 31 & $16(51.6)$ & $7(22.58)$ & $5(16.12)$ \\
\hline Gentamicin & 45 & $18(40)$ & $8(17.7)$ & $4(8.88)$ \\
\hline
\end{tabular}



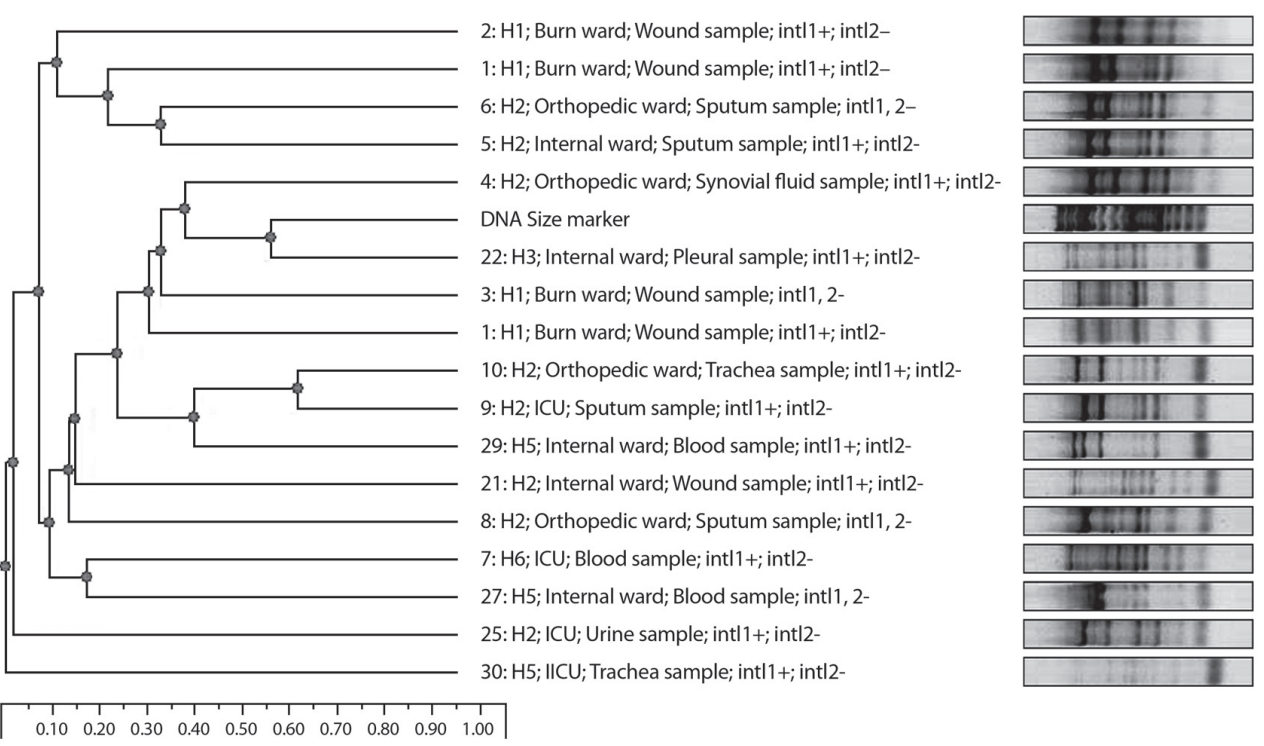

Fig. 5. UPGMA dendogram illustrating the relationships between sample origins, hospitals, wards and the existence of class 1 and 2 integron genes among the genotypes of $A$. baumannii isolates.

bored different integrons. Ceftriaxone and cefotaxime resistant isolates were the most common intI 1 harboring isolates $(58.76 \%)$, followed by ceftriaxone and cefepime with $58.73 \%$ and $58.58 \%$, respectively. However, tetracycline resistant isolates were the most common intI 2 harboring isolates $(22.58 \%)$, followed by gentamicin and amikacin with $17.7 \%$ and $16.12 \%$, respectively (Figs 3, 4). Amplification of the integron gene cassettes of the integrase positive isolates gave PCR products of various sizes ranging from $100 \mathrm{bp}$ to $2.5 \mathrm{~kb}$ (Fig. 4). Distribution of the integron gene cassettes among integrase positive isolates was accounted for $10 \%(n=10)$. Various amplicons of integron gene cassettes were not seen among all integrase positive isolates. The correlations between REP-genotype, different hospitals, wards, sample origins and the existence of integrons are shown in dendogram (Fig. 5).

\section{Discussion}

Acinetobacter baumannii is typically resistant to various antimicrobial agents such as penicillins, cephalosporines, macrolides, aminoglycosides, tetracyclines and fluoroquinolones (Wang et al., 2007).

Because of the multidrug resistance and tendency to spread in hospital population, A. baumannii has a special clinical significance, requiring epidemiologic monitoring as a measure for control of nosocomial infection.

On the basis of the sequence of integrase gene, integrons are divided into at least six classes, with class 1 integron being the most common among the clinical isolates of Gram-negative bacteria, including acineto- bacters (Koeleman et al., 2001; Turton et al., 2005). It seems that class 2 integrons were rarely detected in Acinetobacter spp., but class 3 integrons were not detected in those bacteria at all (Ploy et al., 2000; Koeleman et al., 2001; Turton et al., 2005).

PCR detecting integrase gene used has advantages over the integron cassette PCR in screening for integrons, in that it is designed to give a small product which is easily amplified. Integron cassette PCR can give a negative result even when the integrons are present, if the cassette array is difficult to amplify or if there are no cassettes present. The PCR detecting integrase gene was simple, reliable, and easy to perform (Turton et al., 2005).

In the current study a high prevalence of intI 1 and intI 2 was found among multidrug resistant A. baumannii strains, isolated from different specimens. The results related to class 1 integron were in concordance with other studies (Gonzalez et al., 1998; Seward 1999). Although some studies clarified the presence of intI 2 among A. baumannii strains, only $14 \%$ of the isolates in this study seemed to harbor this class of integrons. These findings are relatively significant since most studies report that class 2 integrons are not found or are found in low rates among A.baumannii strains (Ploy et al., 2000; Turton et al., 2005). Class 3 integron was not found among A.baumannii strains, which was in accordance with other reports (Ploy et al., 2000). Although amplicons with variable sizes were found in integron gene cassette, in agreement with other studies, these variable amplicon could not be detected among all integrase positive strains (Turton et al., 2005). 
Antibiotic resistance is an important factor in the spread of nosocomial infection. It is generally considered that the existence of integrons confers the advantage of antibiotic resistance upon the strains. Among the multiresistant strains described in this study, there were still some strains which did not contain integrons (of classes 1 and 2 at least); however, most of them were susceptible to gentamicin, imipenem, and ampicillin-sulbactam.

Integrons containing the same organization of cassettes were found in various REP genotypes, suggesting horizontal transfer of integrons, also reported in other studies (Sallen et al., 1995; Seward 1999). In addition, the promoter sequences were mostly conserved, even in isolates from different countries with distinct selective pressure, suggesting that acquisition of resistance is likely due to transfer of entire integrons via plasmids and/or transposons rather than of individual cassettes (Ploy et al., 2000). In concordance with other studies, it was proven that the isolates of the same genotype possess different integrons and in the same way, the unrelated isolates with different genotypes could contain the same integrons.

Similar 2.5-kb integrons, with integron cassettes, found by PCR in the present study, have been widely found in isolates of European clones I and II from many countries (Nemec et al., 2004; Turton et al. 2005). The 2.5 -kb integron has also been found in a number of outbreak strains of A. baumannii of different genotypes in Italy, Russia and Ireland (Gombac et al., 2002; Zarrilli et al., 2004; Turton et al., 2005). In conclusion, integrons could be a feature of epidemic strains or clones of A. baumannii currently found in Iran. Information on both the genotype and integron type is useful in epidemiological studies. The association of integrons with epidemic behaviors merits further studies.

\section{Acknowledgment}

This work was supported by Ilam University of Medical Sciences. We acknowledge the microbiology lab workers of Ilam University of Medical Sciences who cooperated in this work.

\section{Literature}

Akbari M., M. Niakan, M. Teherikalani, M.M. Feizabadi, N.A. Azadi, S. Soroush, M. Emaneini, A. Abdolkarimi, A. Maleki and A. Hematian. 2010. Rapid identification of Iranian Acinetobacter baumannii strains by single PCR assay using bla OXA-51-like carbenemase and evaluation of the antimicrobial resistance profiles of the isolates. Acta Microbiol. Immunol. Hung. 57: 87-94. Bou, G., G. Cervero, M.A. Dominguez, C. Quereda and J. Martinezeltran. 2006. PCR-based DNA fingerprinting (REP-PCR, AP-PCR) and pulsed-field gel electrophoresis characterization of a nosocomial outbreak caused by imipenem- and meropenem-resistant Acinetobacter baumannii. Clin. Microbiol. Infect. 6: 635-643
Clinical and Laboratory Standard Institute. 2006. Performance Standards for Antimicrobial Disk Susceptibility tests; $9^{\text {th }}$ for informational Supplement, M2-A9.Clinical and Laboratory Standards Institute, Wayne, $\mathrm{Pa}$.

von Dolinger de Brito D., E.J. Oliveira, V.O. Abdallah, A.L. da Costa Darini and P.P. Filho. 2005. An outbreak of Acinetobacter baumannii septicemia in a neonatal intensive care unit of a university hospital in Brazil. Braz. J. Infect. Dis. 9: 301-309.

Fontana C, M. Favaro, S. Minelli, M.C. Bossa, G.P. Testore, F. Leonardis, S. Natoli and C. Favalli. 2008. Acinetobacter baumannii in intensive care unit: a novel system to study clonal relationship among the isolates. BMC Infect. Dis. 8: 79.

Feizabadi M.M., B. Fathollahzadeh, M. Taherikalani, M. Rasoolinejad, N. Sadeghifard, M. Aligholi, S. Soroush and S. Mohammadiegane. 2008. Antimicrobial susceptibility patterns and distribution of blaOXA genes among Acinetobacter spp. Isolated from patients at Tehran hospitals. Jpn. J. Infect. Dis. 61: 274-278.

Gallego L. and K.J. Towner. 2001. Carriage of class 1 integrons and antibiotic resistance in clinical isolates of Acinetobacter baumannii from northern Spain. J. Med. Microbiol. 50: 71-77.

Gonzalez G., K. Sossa, H. Bello, M. Dominguez, S. Mella and R. Zemelman. 1998. Presence of integrons in isolates of different biotypes of Acinetobacter baumannii from Chilean hospitals. FEMS Microbiol. Lett. 161: 125-128.

Gombac F., M.L. Riccio, G.M. Rossolini, C. Lagatolla, E. Tonin, C. Monti-Bragadin, A. Lavenia and L. Dolzani. 2002. Molecular characterization of integrons in epidemiologically unrelated clinical isolates of Acinetobacter baumannii from Italian hospitals reveals a limited diversity of gene cassette arrays. Antimicrob. Agents. Chemother. 46: 3665-3668.

Koeleman J.G, M.W. van der Bijl, J. Stoof, C.M. VandenbrouckeGrauls and P.H. Savelkoul. 2001. Antibiotic resistance is a major risk factor for epidemic behavior of Acinetobacter baumannii. Infect. Control. Hosp. Epidemiol. 22: 284-288.

Navia M.M., J. Ruiz and J. Vila. 2002. Characterization of an integron carrying a new class D beta-lactamase (OXA-37) in Acinetobacter baumannii. Microb. Drug. Resist. 8: 261-265.

Nemec A., L. Dolzani, S. Brisse, P. van den Broek and L. Dijkshoorn. 2004. Diversity of aminoglycoside-resistance genes and their association with class 1 integrons among strains of panEuropean Acinetobacter baumannii clones. J. Med. Microbiol. 53: 1233-1240.

Peleg A.Y, H. Seifert and D.L. Paterson. 2008. Acinetobacter baumannii: emergence of a successful pathogen. Clin. Microbiol. Rev. 21: 538-582.

Ploy M.C, F. Denis, P. Courvalin and T. Lambert. 2000. Molecular characterization of integrons in Acinetobacter baumannii: description of a hybrid class 2 integron. Antimicrob. Agents. Chemother. 44: 2684-2688.

Sallen B., A. Rajoharison, S. Desvarenne ans C. Mabilat. 1995. Molecular epidemiology of integron-associated antibiotic resistance genes in clinical isolates of enterobacteriaceae. Microb. Drug. Resist. 1: 195-202.

Seward R.J. 1999. Detection of integrons in worldwide nosocomial isolates of Acinetobacter spp. Clin. Microbiol. Infect. 5: 308-318.

Srinivasan V.B, G. Rajamohan, P. Pancholi, K. Stevenson, D. Tadesse, P. Patchanee, M. Marcon and W.A. Gebreyes. 2009. Genetic relatedness and molecular characterization of multidrug resistant Acinetobacter baumannii isolated in central Ohio, USA. Ann. Clin. Microbiol. Antimicrob. 8: 21.

Turton J.F, M.E. Kaufmann, J. Glover, J.M. Coelho, M. Warner, R. Pike and T.L. Pitt. 2005. Detection and typing of integrons in epidemic strains of Acinetobacter baumannii found in the United Kingdom. J. Clin. Microbiol. 43: 3074-3082. 
Taherikalani M., B. Fatolahzadeh, M. Emaneini, S. Soroush and M.M. Feizabadi. 2009. Distribution of different carbapenem resistant clones of Acinetobacter baumannii in Tehran hospitals. New Microbiol. 32: 265-271.

Taherikalani M., G. Etemadi, K.N. Geliani, B. Fatollahzadeh, S. Soroush and M.M. Feizabadi. 2008. Emergence of multi and pan-drug resistance Acinetobacter baumannii carrying blaOXA-type -carbapenemase genes among burn patients in Tehran, Iran. Saudi. Med. J. 29: 623-624.
Wang H., P. Guo, H. Sun, H. Wang, Q. Yang, M. Chen, Y. Xu and Y. Zhu. 2007. Molecular epidemiology of clinical isolates of carbapenem-resistant Acinetobacter spp. from Chinese hospitals. Antimicrob. Agents. Chemother. 51: 4022-4028.

Zarrilli R., M. Crispino, M. Bagattini, E. Barretta, A. Di Popolo, M. Triassi and P. Villari. 2004. Molecular epidemiology of sequential outbreaks of Acinetobacter baumannii in an intensive care unit shows the emergence of carbapenem resistance. J. Clin. Microbiol. 42: 946-953. 